\title{
DESEJO DE RECONHECIMENTO: BELEZA AMERICANA À LUZ DE HEGEL
}

\author{
Tomas Farcic Menk ${ }^{1}$ \\ Universidade Federal de Alagoa (UFAL) \\ https://orcid.org/0000-0002-1398-2248 \\ E-mail: tomas_farcic@yahoo.com.br
}

\section{RESUMO:}

Este artigo pretende fazer uma leitura do filme Beleza Americana utilizando-se da filosofia hegeliana, mais especificamente, da assim chamada dialética do senhor e do escravo. Para realizar essa tarefa dividimos nosso texto em três momentos: 1 - analisamos alguns aspectos de como se instaura uma relação entre consciências de si na vida criando, portanto, relações de dominância (senhor) e subordinação (escravo) em relações intersubjetivas. A contraposição entre os dois elementos determina que, para que haja reconhecimento, uma consciência de si deve subjugar a outra segundo sua vontade, ou seja, uma vontade é reconhecida (a do senhor) enquanto a outra é reconhecedora (a do escravo). 2 - uma apresentação de elementos centrais do filme como pano de fundo para nossa análise. 3 - tecemos um comentário do filme baseado nos elementos conceituais apresentados no item um, demonstrando como o filme pode ser compreendido como uma tentativa do protagonista de sair da indiferenciação total, estabelecer uma luta para ser reconhecido e, finalmente, sendo reconhecido em seus desejos.

PALAVRAS CHAVES: Hegel; Cavell; Reconhecimento; Beleza Americana.

\section{DESIRE OF RECOGNITION: AMERICAN BEAUTY IN THE LIGHT OF HEGEL}

\begin{abstract}
:
With this paper, we aim to discuss the movie American Beauty under the light of the Hegelian philosophy or, more specifically, of the so-called dialectic of the master and the slave. To accomplish this task, we divided our text into three moments: 1 - we analyze some aspects relating to how the relationship among one's consciousnesses of oneself is established in life, creating dominance (lord) and subordination (slave) relations in intersubjectivity relations. The contrast between the two elements determines that, in order to achieve recognition, a consciousness must subdue the other according to its will, that is, one will is recognized (that of the master) whereas the other is the recognizer (that of the slave). 2 - we present central elements of the film as the background for our analysis. 3 - we critically discuss the film based on the conceptual elements presented in item one, demonstrating to what extent the film can be understood as an attempt by the protagonist to overcome the total indifferentiation, to establish a life and death struggle, and finally to be recognized in his desires.
\end{abstract}

KEYWORDS: Hegel; Cavell; Recognition; American Beauty.

${ }^{1}$ Doutor em Filosofia pela Universidade Federal do Rio Grande do Sul (UFRGS), Porto Alegre - RS, Brasil. Professor da Universidade Federal de Alagoa (UFAL), Maceió - AL, Brasil.

MENK, Tomas Farcic. Desejo de reconhecimento: beleza americana à luz de Hegel. Griot : Revista de Filosofia, Amargosa-BA, v.18, n.2, p.448-458, dezembro, 2018. 


\title{
Introdução
}

Jane: Preciso de um pai que dê exemplo, não de um idiota que fica excitado toda a vez que trago uma amiga da escola. Que imbecil. Alguém tinha que acabar com ele.

Ricky: Quer que eu o mate?

Jane: Quero. Você o faria?

É com este diálogo forte, de uma filha querendo matar o pai, que começa o filme Beleza Americana. Ele nos mostra a face mais perturbadora da luta de vida e morte pelo reconhecimento, tal como proposta por Hegel na Fenomenologia do Espírito. O foco do nosso trabalho será apresentar esta face, ou seja, o conceito de desejo e reconhecimento em Hegel, tal como apresentada na Fenomenologia do Espirito $^{2}$, tendo como ponto de partida uma citação de Cavell em Pursuits of Happiness: The Hollywood Comedy of Remarriage. Em um segundo momento, utilizaremos estes conceitos apresentados para a análise do filme propriamente dito. A ideia deste trabalho surgiu da seguinte frase de Cavell:

\begin{abstract}
Nossos filmes podem ser entendidos como parábolas de uma fase do desenvolvimento da consciência no qual a luta é para a reciprocidade ou igualdade de consciência entre uma mulher e um homem, um estudo das condições em que essa luta por reconhecimento (como afirmou Hegel) ou a exigência de reconhecimento ${ }^{3}$ (como já disse) é uma luta pela liberdade mútua, especialmente das opiniões que cada um detém do outro. Isto dá aos filmes de nosso gênero um elenco utópico. Eles abrigam uma visão que eles sabem não pode ser totalmente domesticado, habitado, no mundo que conhecemos. Eles são romances. Mostrando-nos as nossas fantasias, eles expressam a agenda interna de uma nação que concebe anseios utópicos e compromissos para si. (CAVELL, 1981, p. 17). ${ }^{4}$
\end{abstract}

Esta é a primeira aparição do termo reconhecimento em PH. Embora nesta obra Cavell estude uma classe de filmes que não se aplique especificamente à 'Beleza Americana', e tampouco Hegel utilize este termo para estabelecer especificamente a relação entre gêneros (embora possa se prestar a isso), o termo reconhecimento aqui evoca de forma precisa a sua conceitualização na FE. Hegel caracteriza o reconhecimento como uma luta onde uma autoconsciência quer ser reconhecida por outra autoconsciência, e esta luta pode implicar em liberdade, mas também pode resultar em morte e subordinação. Também se deve destacar que em Hegel, de fato, todas as autoconsciências ${ }^{5}$ são iguais inicialmente, e o que desequilibra esta balança é o conflito que estas consciências de si irão realizar ao se relacionarem.

\footnotetext{
${ }^{2}$ De agora em diante como FE.

3 Traduzimos tanto recognition como acknowledgment por reconhecimento. Embora recognition possa assumir outras interpretações, esta é a que melhor compactua com o termo hegeliano.

4 Tradução nossa do original: Our films may be understood as parables of a phase of the development of consciousness at which the struggle is for the reciprocity or equality of consciousness between a woman and a man, a study of the conditions under which this fight for recognition (as Hegel put it) or demand for acknowledgment (as I have put it) is a struggle for mutual freedom, especially of the views each holds of the other. This gives the films of our genre a Utopian cast. They harbor a vision which they know cannot fully be domesticated, inhabited, in the world we know. They are romances. Showing us our fantasies, they express the inner agenda of a nation that conceives Utopian longings and commitments for itself. (PH 17)

${ }^{5}$ Utilizaremos tanto autoconsciência como consciência de si como tradução de selbstbewusstsein.
}

MENK, Tomas Farcic. Desejo de reconhecimento: beleza americana à luz de Hegel. Griot : Revista de Filosofia, Amargosa-BA, v.18, n.2, p.448-458, dezembro, 2018. 


\section{Desejo, Reconhecimento e a luta de vida e morte em Hegel}

Para compreendermos a função e a definição conceitual de reconhecimento em Hegel é necessário antes estabelecer a posição que este ocupa no percurso da FE. Esta obra apresenta "a consciência em seu movimento progressivo, desde a oposição primeira e imediata dela e do objeto até o saber absoluto. Esse caminho percorre todas as formas da relação da consciência com o objeto e tem como resultado o conceito da ciência" (HEGEL, 2016, pg. 51). O que Hegel propõe na FE é um desenvolvimento progressivo da consciência desde seus aspectos mais primitivos até seus aspectos mais elevados. Este percurso da consciência, do saber imediato (o mais básico e elementar) até o saber absoluto (o mais desenvolvido), tem várias etapas de progressivo desenvolvimento. Podemos dividir o estágio dito do 'homem singular', em sua vivência própria no mundo em três, a saber: consciência, consciência-de-si e razão, onde a segunda se desenvolve da primeira, e a terceira se desenvolve da segunda.

A primeira etapa, a da simples consciência, mostra a relação do homem com os objetos externos a ele, ou seja, mostra como o homem pode conhecer e se relacionar com o mundo ao seu redor, como por exemplo, poder ver e conhecer uma árvore, uma casa, uma pedra. Ela também se desenvolve em três momentos, o saber imediato, a percepção e o entendimento. Basicamente, o que é importante para nós é saber que a consciência é a relação do homem com os objetos do mundo.

Quando se realiza a passagem da consciência para a consciência de si, a coisa com a qual a consciência se relaciona também muda. Se a consciência se relacionava com um objeto, a consciência de si se relaciona com outra consciência de si, mediados pela vida ${ }^{6}$, meio no qual, todas as autoconsciências se relacionam. Assim, eu só sei que eu existo por que tenho certeza que da existência de outros 'eus' em relação a mim. Hegel apresenta, portanto, algo inovador na filosofia no que se refere a concepção do eu e da consciência de si. Para ele não é possível a existência de uma consciência de si que não seja em relação. Ela não é apenas propriedade de um sujeito pensante isolado do mundo, mas sim, um pensar que está em relação a algo, a outra coisa. A consciência de si não é propriedade nem do sujeito pensante nem do seu objeto (neste caso, outra consciência de si), mas sim da relação entre ambos. Há de se notar também, que esta relação não é imóvel ou fixa, mas muito antes, movimento. Isso significa dizer que existe uma interdependência entre os dois elementos, a mudança de um implica na mudança do outro, pois o movimento de um interfere na existência do outro.

Assim como só sabemos que existe a luz por que existe o escuro, ou que existe o dia porque existe à noite, também só sabemos que temos consciência porque temos um mundo oposto a nós, onde é possível pensar acerca dele ${ }^{7}$ Não há

\footnotetext{
${ }^{6}$ A vida possui um sentido amplo em Hegel. Ela pode ser desde a vida biológica dos seres vivos até a vida ética, ou seja, a vida dos homens em sociedade. Aqui, consideramos a vida como a propriedade inerente a todos os seres animados, ou seja, duas consciências de si só se relacionam por estarem vivas. Embora a vida englobe também os animais, neles não há reconhecimento, pois segundo Hegel, eles não pensam e não tem consciência de individualidade. Vide ROSENFIELD, D. L. Como se pode falar da vida em Hegel?

${ }^{7} \mathrm{Na}$ dialética hegeliana (talvez de outros autores também, mas não queremos ampliar demasiadamente o tema) é necessário sempre haver uma oposição que determina e esclarece (aufklärung) alguma coisa.
}

MENK, Tomas Farcic. Desejo de reconhecimento: beleza americana à luz de Hegel. Griot : Revista de Filosofia, Amargosa-BA, v.18, n.2, p.448-458, dezembro, 2018. 
possibilidade de existir uma consciência sem relação a um objeto. E se a consciência ${ }^{8}$ é posta em relação com um objeto, a consciência de si é posta em relação com outra consciência de si.

A consciência de si, nesse sentido, é a experiência do homem que se defronta com outro homem consciente de si, assim, para Hegel, o homem só se concebe de fato na vida em sociedade. A consciência de si é o percurso/trajeto do homem que busca se conhecer, e faz isso ao perceber que está em relação a outro ser pensante. Assim, o Eu pode ser encarado da seguinte forma:

A consciência ${ }^{9}$ era saber de um Outro, (objeto - gegenstand) saber do mundo sensível em geral; ao contrário, a consciência de si é saber de si; Exprime-se pela identidade do Eu = Eu - Ich bin ich. O Eu, que é objeto, é o objeto para si próprio: é, ao mesmo tempo, o sujeito e o objeto, põe-se para si. (HYPPOLITE, 1999, pg. 172).

É preciso entender que esta relação entre duas consciências de si (ou de outra forma, entre duas pessoas) só é possível se houver algum elemento comum a todas as consciências de si que possibilitem elas coexistirem e se confrontarem. $\mathrm{O}$ elemento de pano de fundo comum a todas se chama, como dito anteriormente, vida. Ora, se a consciência de si está 'só existe' por meio da vida, Hegel afirma que o desejo $\left(\right.$ begierde $\left.^{10}\right)$ primordial e primeiro desta autoconsciência é preservar a vida e afastarse da morte (uma coisa até óbvia; praticamente quase todos os seres vivos querem continuar vivos).

Até aqui já sabemos que uma autoconsciência precisa se relacionar com outra para saber que existe, que elas se relacionam por estarem mediadas (intercedidas) pela vida e que desejam a vida. $O$ desejo é, portanto, a primeira forma de contato do homem com o mundo externo a ele. Todos os homens sentem frio, fome, calor, desejo sexual e, como desejantes, a sua ação é no sentido de satisfazer estes desejos. O desejo sexual, que podemos considerar como a primeira atividade de uma consciência de si se relacionando com outra, é a apropriação do corpo. Não é um desejo meramente discursivo, mas uma confrontação física. Depois do desejo de preservação da vida, o desejo sexual é o estágio mais elementar da autoconsciência. O desejo sexual leva duas pessoas a se confrontarem, pois uma precisa da outra para satisfazê-lo, e este confronto leva as autoconsciências a ter noção de sua corporeidade. Portanto a autoconsciência não é algo meramente discursivo.

Mas o desejo sexual só nos mostra o encontro de duas autoconsciências. $\mathrm{O}$ que nos importa aqui é que elas se relacionam e são desejantes, assim uma tentará impor o seu desejo (não só o desejo sexual que é o primeiro, mas qualquer tipo de

\footnotetext{
8 Esta é uma separação importante é fundamental em Hegel. Devemos sempre lembrar que consciência é diferente de consciência de si. A primeira se refere à relação de um sujeito pensante a um objeto, enquanto que a segunda se refere à relação entre dois sujeitos pensantes. A segunda se desenvolve/evolui da primeira.

${ }^{9}$ Grifo nosso.

10 note que Hegel não utiliza nem lust nem wunsch para designar desejo. Este termo é complicado, pois sua primeira acepção sugere luxuria, mas os interpretes são unanimes em traduzi-lo como desejo (em casos isolados como apetite). $\mathrm{O}$ que Hegel propõe é um desenvolvimento da consciência desde seus aspectos mais primitivos até seus aspectos mais elevados. Ora, o desejo da vida é a vontade básica e elementar de todo ser vivo: continuar a viver, preservar sua vida e fugir da morte. $O$ segundo grau de desenvolvimento do desejo, depois que um ser vivo preservou sua vida, é o desejo/apetite sexual.
}

MENK, Tomas Farcic. Desejo de reconhecimento: beleza americana à luz de Hegel. Griot : Revista de Filosofia, Amargosa-BA, v.18, n.2, p.448-458, dezembro, 2018. 
desejo) sobre a outra e dominá-la. Para Hegel, o primeiro contato das autoconsciências é um encontro onde uma quer dominar a outra, pois cada uma quer realizar o seu desejo. Assim, nasce o reconhecimento, quando duas autoconsciências se confrontam na existência da vida, e uma subjuga a outra, sendo uma a reconhecida e a outra a que confere reconhecimento. "O encontro das consciências de si se manifesta como sua luta para se fazerem reconhecer. O desejo é menos o do amor que o do reconhecimento viril de uma consciência desejante para outra consciência desejante. Logo, o movimento do reconhecimento se manifestará pela oposição entre consciências de si." (HYPPOLITE, 1999, pg. 179). O reconhecimento nasce do conflito estabelecido pelo contato de duas consciências, onde ambas querem impor o seu desejo sobre as outras. Esse movimento é a passagem do em si ao para $\mathrm{si}^{11}$. Ela quer (e precisa) ser reconhecida pela outra consciência. Hyppolite afirma que "Somente sou consciência de si quando me faço reconhecer por outra consciência de si." (HYPPOLITE, 1999, pg. 180), ou seja, uma reconhece (o escravo, ou mais precisamente, o servo) e outra é reconhecida (o senhor).

Esta relação entre consciências de si que querem ser reconhecidas não é um embate amigável ${ }^{12}$. É um duelo de vida e morte entre duas instâncias que querem sobrepujar a outra. Uma quer que a outra a reconheça. "A vocação do espírito do homem não é somente uma luta pela vida, é uma luta para ser reconhecido, uma luta para provar aos outros e provar a si próprio que se é uma consciência autônoma ${ }^{13 "}$ (HYPPOLITE, 1999, pg. 184).

No reconhecimento, o que vemos é a nós mesmos, é um olhar para si por meio o outro. $O$ reconhecimento é como olhar-se no espelho, e conhecer-se implica em conhecer o outro e vice-versa ${ }^{14}$. Como ambos (Si e o Outro) estão em intima relação, o agir de um implica agir sobre o outro, pois para toda ação há uma reação, e o perceber de um é o perceber de outro. Assim, o agir de um conforme o seu desejo, (que quer se apropriar do seu desejo expresso na figura do outro), implica na morte do outro, que tem seu desejo consumido. Se a vida é consciência de si, sua negação é a morte, e reconhecer-se significa, portanto, enfrentar a morte representada pelo Outro. Hyppolite afirma que:

A consciência de si faz, portanto, a experiência da luta pelo reconhecimento, mas a verdade dessa experiência engendra uma outra, a experiência das relações de desigualdade no reconhecimento, a da

\footnotetext{
${ }^{11}$ Em si: existência imediata no mundo; estar no mundo; o imediato.

Para si: Captura deste processo (experiência); saber de si; o mediado; apropriar-se da sua existência.

Em si e para si: Para nós; saber absoluto.

12 Embora Hegel não seja um contratualista e não seja possível falar em 'homem natural' no seu pensamento, pois o homem só se dá em sociedade, poderíamos traçar uma identificação entre o pensamento de Hegel e o de Hobbes, onde o homem é o lobo do homem. Não há espaço para o bom selvagem em Hegel. Para ele, coisas como o altruísmo e benevolência só aparecem no interior da vida ética em sociedade. Num primeiro momento, o que o homem quer é satisfazer sua vontade de reconhecimento sobre o outro, e uma destas autoconsciências será subjugada.

13 Autônoma aqui deve ser entendida como a capacidade de se autodeterminar e não depender de outro. Em uma linguagem mais simples, quer dizer pensar por si mesmo sem ser coagido por outro.

14 Este ponto pode parecer estranho, mas podemos recorrer a uma analogia. Se um explorador inglês, por exemplo, chega a uma tribo africana totalmente desconhecida, ele não conseguirá compreender nada daquela cultura. A única coisa que ele conseguirá fazer é comparar com o que já conhece, e analisá-la segundo seus próprios pontos de vista. Ele não consegue compreender, num primeiro momento, aquela cultura nela mesma.
}

MENK, Tomas Farcic. Desejo de reconhecimento: beleza americana à luz de Hegel. Griot : Revista de Filosofia, Amargosa-BA, v.18, n.2, p.448-458, dezembro, 2018. 
dominação e da servidão. Com efeito, se a vida é a oposição natural da consciência, a morte é também sua negação apenas natural. (HYPPOLITE, 1999, pg. 185.).

Este é a luta de vida e da morte. Desta luta, um sai como reconhecido, o senhor, e outro sai como reconhecedor, o escravo ${ }^{15}$. Há duas formas de se perder esta luta, ou sendo mais fraco e possuindo menos desejo que seu oponente, e assim se configura propriamente a derrota, ou quando uma pessoa, por medo da morte, simplesmente abandona a luta e se coloca voluntariamente como escravo e reconhecedor do desejo do senhor. O senhor por outro lado, é alguém que não tenho medo da morte, empenhou-se numa luta para fazer valer a sua vontade. Hegel afirma que:

$O$ individuo que não ariscou a vida pode bem ser reconhecido com pessoa, mas não alcançou a verdade desse reconhecimento como uma consciência de si independente. Assim como arrisca sua vida, cada um deve igualmente tender a morte do outro. (HEGEL. 2008, pg. 146).

\section{A história}

Beleza Americana é um filme de 1999 dirigido por Sam Mendes ${ }^{16}$ e com roteiro de Allan Ball. $O$ filme é uma narração em terceira pessoa de Lester Burnham (Kevin Spacey) sobre seu último ano de vida até a sua morte. Ele começa com uma cena sobrevoando uma rua, como uma indicação que o narrador já está morto, o que ele confirma logo no início. As primeiras cenas apresenta a família de Lester, composta por sua filha Jane (Thora Birch) e esposa Carolyn (Annette Bening). Jane é uma adolescente comum, insegura com sua autoimagem e rebelde com seus pais. Carolyn é uma esposa dominadora e materialista. O que ambas tem em comum é considerar Lester um fracassado, um pária. Não temos muita informação sobre o emprego deste pai de família, a única coisa que o filme faz referência é a uma revista chamada 'Mídia Mensal'. Mas mais importante do que saber qual é o seu emprego, é saber que ele odeia ele e que está na iminência de ser demitido, aparentemente por um problema financeiro causado por uma falcatrua de um dos donos da revista. $O$ chefe de Lester o pressiona a fazer um relatório sobre a sua utilidade na empresa, coisa que ele se recusa a fazer.

Assim, Lester é pressionado por todos os lados, e todos os consideram um pária. Isso muda quando ele vai assistir uma apresentação de dança de sua filha no colégio, e acaba por se apaixonar por uma amiga dela chamada Angela (Mena Suvari). A partir deste evento, Lester decide mudar de atitude perante a vida, e seu objetivo passa a ser conquistar Angela e ter a menor quantidade de responsabilidade possível. Ele começa a fumar maconha (comprada do Ricky, que é filho do seu vizinho e namorado de sua filha), é despedido, começa a trabalhar numa lanchonete, compra o carro dos seus sonhos e começa a malhar.

\footnotetext{
15 Não devemos interpretar a figura do senhor e o escravo como um mote político ou histórico, seja no mundo grego, romano, egípcio, etc. A luta pelo reconhecimento é uma alegoria criada por Hegel para conceitualizar o primeiro momento de relação entre duas consciências de si, na qual uma tende sobrepor a outra.

${ }^{16}$ Ele é um diretor britânico que até então só havia dirigido peças de teatro. Beleza Americana foi sua estreia como diretor de filmes.
}

MENK, Tomas Farcic. Desejo de reconhecimento: beleza americana à luz de Hegel. Griot : Revista de Filosofia, Amargosa-BA, v.18, n.2, p.448-458, dezembro, 2018. 
Há também duas tramas secundárias. Uma é a da Jane com seu namorado Ricky, que é um traficante e filho de um militar autoritário e fascista, que é o assassino de Lester, e de uma mãe totalmente ausente da realidade. A outra é da Carolyn e seu amante, o Buddy, um bem sucedido (pelo menos é o que aparenta) vendedor de casas. Carolyn vê em Buddy o sucesso que ela mesma não consegue. Lester sabe do adultério de sua mulher, mas não se importa com isso. No final Lester consegue conquistar Angela, mas ao saber que ela é virgem perde o interesse nela. Ele também recusa o assedio do pai de Ricky que era secretamente apaixonado por Lester, e, por vingança, o coronel Frank mata Lester.

\section{Reconhecimento e a beleza americana}

Esse filme e um caso clássico no qual já sabemos o final ${ }^{17}$, no caso, que o protagonista vai morrer. Mas isso não é tão importante, o que nos interessa é saber quando e o por quê. Na primeira narração de Lester ele diz: "Meu nome é Lester Burnham. Este é o meu bairro. Esta é a minha rua. Esta é a minha vida. Tenho 42 anos. Em menos de um ano estarei morto. De certa forma, já estou morto.". É curiosa essa afirmação de que ele já está morto. Podemos interpretar esta passagem como um indiferenciação de Lester com a sua própria vida, ou seja, ele não reconhece seus próprios desejos. Ele já está morto para eles. Ele simplesmente sobrevive, e sua família o trata da mesma forma que ele se vê, como um ninguém, como um pária.

O nosso foco é mostrar que a luta de vida e morte pelo reconhecimento, tal como exposto anteriormente, é análogo ao percurso que Lester desenvolve no decorrer do filme em busca de realizar seus desejos e se fazer reconhecer. No começo do filme ninguém presta atenção a ele e ninguém o reconhece. Lester percebe que isso acontece justamente porque ele mesmo está 'morto' para seus desejos, e o seu reconhecimento não ocorre porque ele não impõe seus desejos. Ele é como um escravo de todos, pois recusou reconhecer os seus desejos em prol dos desejos dos outros (principalmente de Carolyn); o medo da morte (como afirmado anteriormente) o fez abandonar a luta pelo reconhecimento e reconheceu voluntariamente todos como seus senhores. É curioso notar que ele morre ao ser reconhecido por Angela quando ela pergunta como ele está, e assim, morre em paz.

Dado as definições de desejo e reconhecimento, tentaremos transpor esses elementos na nossa interpretação do filme Beleza Americana. O filme começa mostrando a falta de relação e a superficialidade de tratamento entre os elementos de uma família e alguns personagens mais próximos a ela. As cenas quase sempre se dão através de janelas ou filmagens, e quando um personagem tenta reconhecer outro, quase sempre se dá com alguém pensando sobre o outro e observando de longe. Quando as personagens se relacionam pessoalmente quase sempre é de forma superficial e com sorrisos falsos ou o oposto, de forma rude e autoritária e permeada de brigas.

Os personagens não se importam um com o outro porque não se reconhecem, e este não reconhecimento implica em não reconhecer a si mesmo e seus próprios

17 Como por exemplo, o filme "O Assassinato de Jesse James pelo Covarde Robert Ford", onde o título já nos dá o spoiler do final.

MENK, Tomas Farcic. Desejo de reconhecimento: beleza americana à luz de Hegel. Griot : Revista de Filosofia, Amargosa-BA, v.18, n.2, p.448-458, dezembro, 2018. 
desejos. Carolyn, por exemplo, não se preocupa em ser realmente feliz ou satisfazer seus desejos, mas sim em passar uma imagem de realização e sucesso. As casas e os gramados são sempre muito bem cuidados, e a uma primeira vista parece que nelas só moram pessoas felizes, mas no decorrer do filme percebemos que isso não é verdade. Outro bom exemplo é a fala da mãe do Ricky quando este apresenta sua namorada a ela. Esta mulher perturbada diz para Jane não reparar a bagunça em sua casa, enquanto que esta está perfeitamente limpa e organizada. Porém, é a relação entre as pessoas da família que está um caos, escondida atrás de uma primeira aparência de organização e de móveis caros e bonitos. Eles perderam o interesse em si próprio, e consequentemente o interesse na vida e na relação com o outro.

O percurso de Lester no filme será igual ao movimento da consciência de si em busca de reconhecimento. Ela tem que partir do 'em si', do indiferenciado, representado pela 'American way of life' que só se importa com o aparente. Ele quer se reconhecido, porém terá de lutar para conseguir este reconhecimento, e chegar no 'para si'. Ninguém dá o reconhecimento ao outro de bom grado.

Podemos identificar, portanto, o sonho americano como o em si, pois fica somente no imediato, na aparência, não se preocupa com a essência e não reconhece seus próprios desejos. O símbolo máximo talvez seja representado pelo 'rei', um personagem que aparece somente em cartazes ou em situações em que parece ser bem sucedido, embora não saibamos quase nada de sua vida particular. Lester é a pessoa que percebe que está vivendo só a aparência, portanto é infeliz. O momento que ele rompe esta imediaticidade indiferenciada é quando surge o desejo por Ângela. Ele percebe que tem desejos e começa a dar ouvido a eles, quer satisfazê-los. Lester quer a Angela, quer fumar maconha e quer saciar suas vontades. Ele entra em contato com o em si, ou seja, com ele mesmo.

O filme narra, portanto, a luta de Lester pelo reconhecimento. Na verdade ele já estava subjugado, como um verdadeiro escravo em todas as relações estabelecidas na sua vida. Todos são senhores dele, desde seu chefe, sua esposa, e em alguns momentos até a sua própria filha. Isso muda no momento em que se depara com a dança de Angela no colégio de Jane, sua filha. Ele tem uma epifania e algo que estava dormente dentro dele ressurge, mostrando todo seu desejo entorpecido e enjaulado por causa de sua derrota na luta de vida e morte. Porém agora ele quer dar vazão aos seus desejos, e para tanto ele tem que ser reconhecido. Mas isso não será fácil, pois ele é tido como 'escravo' e todos o tratam assim, e ninguém lhe dará o reconhecimento de boa vontade. Ele terá que lutar para ser reconhecido, e lutar contra a própria 'morte'. Hyppolite diz que:

\footnotetext{
Os homens não tem, como os animais, somente o desejo de perseverar em seu ser, o ser-aí (em si) ao modo das coisas; têm o imperioso desejo de se fazerem reconhecer como consciência de si, como elevados acima da vida puramente animal, e essa paixão, para se fazer reconhecer, exige, por seu turno, o reconhecimento da outra consciência de si. (HYPPOLITE, 1999, pg. 184).
}

Após ver Angela dançando Lester muda. Ele redescobre o desejo de viver e a vontade de lutar para ser reconhecido, e dar vazão as suas vontades, ao invés de 
apenas satisfazer as vontades dos outros (os senhores). A imagem que melhor representa esta mudança são as flores tema do filme, que podemos associar ao desejo de Lester. Na relação com Carolyn, as rosas estão cultivadas em canteiros bonitos e muito bem cuidados adubados com casca de ovo. Já no caso de Angela, esta flor aparece em profusão de pétalas caindo ao sabor do vento, livres e em quantidades infinitas. Carolyn cultiva o desejo de Lester em um canteiro para mostrar para os vizinhos, enquanto Angela libera todos os desejos dele ${ }^{18}$.

No seu emprego ele não aceita ser subjugado pelo seu chefe, que injustamente queria demiti-lo, e o enfrenta. Lester diz algo importante ao seu contratante quando este o chama de louco. Ele diz que: "Não [sou louco], sou apenas um homem que não tem nada a perder". Está é a atitude de alguém que está lutando pelo reconhecimento; ele tem que lutar contra a morte, aqui representada pela sua garantia financeira de subsistência, e quem luta contra a morte aposta tudo o que tem, ou seja, aposta sua vida.

Outra luta de vida e morte que ele empreende é contra a sua esposa. Ele impõe a sua vontade de reconhecimento a ela, não se importando com os riscos ou consequências. Isso é bem retratado na cena em que Lester se masturba na cama. Ao Carolyn reagir ao ato de Lester, este não recua e reafirma sua posição. Ele não teme as possíveis (e grandes) perdas desde ato, como, por exemplo, acabar com seu casamento (como de fato estava ocorrendo).

Ao modificar nossa autoconsciência modificamos os outros ${ }^{19}$. Assim, quando Lester reconhece seu desejo (de si mesmo), ele impõe aos outros o seu desejo. Estes outros, que eram senhores de Lester não querem permitir, pois encaram este movimento como o movimento da sua própria morte. Assim, as pessoas em seu entorno querem matá-lo, como uma atitude quase que de autopreservação. Lester ao seu conhecer e se reconhecer obrigou que os outros personagens também se conhecessem e se reconhecessem. A sua mulher não aceita ser tratada como ela realmente é, mesquinha e superficial. O seu vizinho, o coronel Frank, se descobre como homossexual.

No final de todo este percurso por reconhecimento, finalmente Lester consegue ficar a sós com Angela em sua casa, porém no momento que eles vão consumar o ato, ela confessa que é virgem. Esta declaração faz Lester recuar e desistir do sexo. Nesse sentido, desejar, na verdade, é saciar o próprio desejo, e o que vemos no outro é a nossa própria vontade projetada. Então não era a amiga de sua filha que ele realmente desejava, mas sim, possuir uma menina que representava algo no seu desejo. No momento que Angela se mostra diferente do desejo de Lester, este desaparece. Então eles vão para a cozinha e a menina faz uma pergunta fundamental para Lester: "Como você está?". Ele finalmente foi reconhecido. Agora ele já pode morrer em paz, pois sua luta por reconhecimento já foi vencida.

Por fim, podemos considerar a narração de Lester como o em si e para si (perspectiva do 'saber absoluto', pois ele viveu e conhece toda a sua história), pois é a

\footnotetext{
${ }^{18}$ Vale lembrar, que esta flor, a Beleza Americana, é uma espécie hibrida, campeã de vendas nos EUA, e que ela não se polimeriza naturalmente. É preciso que o homem faça um enxerto.

${ }^{19}$ Se estamos todos em relação (homens, objetos, animais e tudo o que existe), é plausível argumentar que estas coisas em relação influenciem e alterem umas as outras. Esse seria, segundo Hegel, o 'movimento' da realidade, da efetividade, do mundo.
}

MENK, Tomas Farcic. Desejo de reconhecimento: beleza americana à luz de Hegel. Griot : Revista de Filosofia, Amargosa-BA, v.18, n.2, p.448-458, dezembro, 2018. 
narração de uma pessoa (consciência de si) que viveu, (o em si) reconheceu a sua existência, passando pelo processo da experiência de autoconhecimento (para si) e depois de toda a sua vivencia ele consegue ver totalidade de sua trajetória no mundo e a sua luta pelo reconhecimento (o em si e para si, ou a visão do saber absoluto, pois Lester, enquanto narrador, possui uma visão onisciente). Ele e em si e para si, pois viveu e experimentou esta luta de reconhecimento. Enquanto ele vivia ele era em si, e depois reviveu a sua história ele se apropria do para si, pois ele pode transformar toda a sua experiência em conhecimento, mas não qualquer tipo de conhecimento, mas um autoconhecimento, um conhecimento dos seus próprios desejos e ambições, que conseguiu realizar por fim, e unir o em si (o simples existir) como o conhecimento da sua existência (o para si).

\section{Considerações finais}

Embora o filme não tenha uma temática hegeliana ou nem mesmo filosófica propriamente, é possível fazer uma leitura das últimas horas de vida de Lester com a disputa de vida e morte para a conquista do reconhecimento. Lester sai da indiferença do não reconhecimento, da vida em si, da fuga ou do medo da luta que obrigatoriamente temos que travar para adquirir reconhecimento. Esse medo em partes é justificado, pois a luta requer perdas e destruições, ou seja, a perda e a quebra da sua vida familiar. É cômodo não precisar lutar e apenas reconhecer, pois assim não precisa enfrentar o outro nem se arriscar a morrer (como de fato acontece com Lester). Porém o preço é muito alto, é abdicar de seus desejos e de seu reconhecimento, ainda mais, é abdicar-se de si mesmo. Lester não estava mais disposto a pagar esse preço, mesmo que pagasse com a vida. 


\section{Referências}

BELEZA Americana. Direção: Sam Mendes. Los Angeles: Dream Works, 1999

CAVELL, Stanley. Pursuits of Happiness: The Hollywood Comedy of Remarriage. Cambridge: Harvard University Press, 1981.

HEGEL, G. W. F. Ciência da Lógica: A doutrina da essência. Petrópolis: Vozes 2017. . Ciência da Lógica: A doutrina do ser. Petrópolis: Vozes 2016.

. Fenomenologia do Espírito. Tradução de Paulo Menezes, $5^{\mathrm{a}}$ Ed.

Petropolis: Vozes, 2008.

HYPPOLITE, Jean. Gênese e estrutura da Fenomenologia do espírito de Hegel. Tradução de Sílvio Rosa Filho. São Paulo: Discurso Editorial, 1999.

ROSENFIELD, D. L. Como se pode falar da vida em Hegel? Revista Controvérsia, São Leopoldo v. 4, n. 2 (2008).

Autor(a) para correspondência: Tomas Farcic Menk, Universidade Federal de Alagoa, Insituto de Ciências Humanas, Comunicação e Artes, Avenida Lourival Melo Mota, s/n, Cidade Universitária, CEP 57072-900, Maceió - AL, Brasil.tomas_farcic@yahoo.com.br 